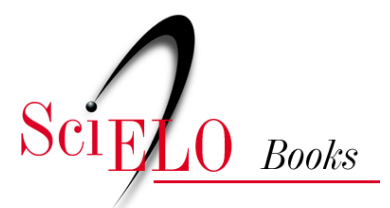

\title{
Capítulo 2. Ovinocaprinocultura e os principais helmintos gastrintestinais
}

\author{
Breno de Holanda Almeida
}

Gizele Lannay Furtuna dos Santos

\section{SciELO Books / SciELO Livros / SciELO Libros}

ALMEIDA, B. H., and SANTOS, G. L. F. Ovinocaprinocultura e os principais helmintos gastrintestinais. In: BEZERRA, A. C. D. S., and SILVA, M. D. C., eds. Fitoterapia e a Ovinocaprinocultura: uma associação promissora [online]. Mossoró: EdUFERSA, 2018, pp. 27-48. ISBN: 978-85-57570-91-7. https://doi.org/10.7476/9786587108643.0004.

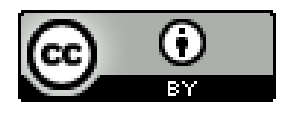

All the contents of this work, except where otherwise noted, is licensed under a Creative Commons Attribution 4.0 International license.

Todo o conteúdo deste trabalho, exceto quando houver ressalva, é publicado sob a licença Creative Commons Atribição 4.0. 


\title{
OVINOCAPRINOCULTURA E OS PRINCIPAIS HELMINTOS GASTRINTESTINAIS
}

\author{
Breno de Holanda Almeida \\ Gizele Lannay Furtuna dos Santos
}

\section{INTRODUÇÃO}

A prática da criação de caprinos e ovinos, no Brasil e principalmente no Nordeste Brasileiro, é um costume que foi herdado desde o período da colonização, em especial pela questão de tais espécies serem mais integradas às condições ambientais e climáticas desfavoráveis do que a maioria das outras espécies (CAVALCANTE \& BARROS, 2005). Para os pequenos criadores, por possuírem poucos recursos e conhecimentos sobre manejo, que vão da alimentação ao sanitário, torna-se comum a morte de mais de $20 \%$ dos animais nascidos e o desenvolvimento retardado dos que conseguem sobreviver (GUIMARÃES FILHO \& ATAIIDE JÚNIOR, 2009), sendo as parasitoses gastrintestinais um grave problema sanitário, responsáveis pelas maiores perdas econômicas e de rebanhos.

A helmintologia é o estudo dos helmintos, no qual estão enquadrados os filos Nemathelminthes e Platyhelminthes. Os integrantes do primeiro filo são classificados como vermes redondos, com parede do corpo chamada de cutícula, e no segundo filo se tem a classificação de vermes achatados, com parede do corpo chamada de tegumento. Ambos os filos possuem espécies que parasitam 
o trato digestivo do hospedeiro, conhecidos como helmintos gastrointestinais (MONTEIRO, 2007). Estes são responsáveis por causarem diversas doenças em rebanhos, entre elas, desnutrição, estados convulsivos, distúrbios gastrintestinais, avitaminoses e prejuízo ao desenvolvimento dos animais (SOUZA, 2013).

Os pequenos ruminantes são, geralmente, o foco de infecção pelos parasitas gastrintestinais, especialmente em zonas úmidas e temperadas, e em animais de pastejo, causando lesões que podem atingir desde o abomaso até o intestino (COSTA, 2007). As helmintoses gastrintestinais em pequenos ruminantes apresentam grande expressão devido às práticas de manejo e tecnologias inadequadas observadas em alguns sistemas produtivos (LIMA, 2011).

\section{OVINOCAPRINOCULTURA}

A ovinocaprinocultura corresponde a uma atividade econômica e social no Brasil descendente de costumes e tradições ancestrais, através da qual o país, atualmente, se encontra como um grande produtor mundial. Com boa adaptabilidade aos ecossistemas locais, representa considerável alternativa de trabalho e renda pela venda da pele e produção de alimentos com alto valor biológico (MORAES NETO et al., 2003). A criação desses pequenos ruminantes é intensiva na região Nordeste (PINHEIRO et al., 2000), com destaque para os caprinos e ovinos deslanados, onde se tornou alternativa viável como fonte de renda principalmente para as pequenas e médias propriedades rurais (CUNHA et al., 2007).

A utilização dos pequenos ruminantes na região Nordeste do Brasil tem os primeiros registros a partir de 1560. Porém, foi no fim dos anos 1990 que essa atividade ganhou notoriedade. O sucesso da ovinocaprinocultura está relacionado às suas características básicas, 
como pequeno porte dos animais, resistência às condições climáticas e ambientais, menor exigência alimentar para ganho de peso e produção de leite, além da rápida procriação (ALVES et al., 2013). Apesar das vantagens, o manejo inadequado interfere diretamente na produtividade dos rebanhos (AZEVEDO, 1982), pois pode ocasionar o surgimento de patologias e uma considerável redução na produção, podendo causar portanto, prejuízos econômicos ao produtor (CALDAS et al., 1989).

Em definição, o parasitismo é a interação ecológica entre indivíduos de diferentes espécies nas quais hospedeiros e parasitas mantêm uma associação unilateral, íntima e direta com certo grau de dependência metabólica por parte dos parasitas (POULIN, 2007). Os efeitos resultantes dessas relações desarmônicas representam danos significativos aos hospedeiros (TAYLOR et al., 2007).

Com relação à produção animal, o parasitismo é um dos principais limitantes, impondo diversos desafios no combate às enfermidades por eles geradas (MOLENTO, 2004), tendo a infecção como resultante da relação desarmônica entre hospedeiro e parasita que, via os nematoides gastrintestinais, tem se apresentado como uma das principais causas de perdas econômicas para os produtores de pequenos ruminantes no Brasil, como caprinos e ovinos, e em outras partes do mundo (COOP \& KYRIAZAKIS, 2001).

\section{HELMINTOS GASTRINTESTINAIS}

Uma das mais relevantes dificuldades da atividade com caprinos e ovinos são as parasitoses gastrintestinais, que evidenciam um grave problema sanitário, causando sérios entraves na produção e com possibilidade de prejudicar economicamente a criação (COSTA et al., 2011). Os sintomas causados pelas infecções divergem de acordo com a idade do animal ou espécie do parasita. Porém, podem ser observados como 
principais sintomas a anemia, a perda de peso (NEVES, 2012), baixas taxas reprodutivas, pelo arrepiado, edema de barbela e, em casos mais extremos, decúbito e óbito (SAGRILO et al., 2003).

A sensibilidade dos pequenos ruminantes aos parasitas provavelmente está associada à sua descendência na região desértica da Ásia Central, caracterizada como uma região desfavorável aos parasitas, pela baixa umidade e devido ao fato de os animais pastarem principalmente arbustos em diferentes locais, diminuindo seu contato com as fezes e, consequentemente, diminuindo as chances de infecções. Nesse contexto, pode ocorrer ausência do desenvolvimento de imunidade contra as infecções parasitárias (SOTOMAIOR et al., 2009).

No Brasil, o clima é um fator favorável ao ciclo de vida desses parasitas, fornecendo condições de sobrevivência dos ovos na pastagem e, assim, aumentando as chances de infecção ou reinfecção animal. Portanto, os sistemas de produção que apresentam erros de manejo, com ênfase na superlotação, ocasionam grande risco de reinfecção devido à pastagem coletiva no mesmo local favorecer a disseminação de patologias (MOLENTO, 2004).

\section{NEMATOIDES GASTRINTESTINAIS}

Os nematoides são um grupo bastante diverso de espécies animais de corpo cilíndrico e alongado que constituem o Filo Nematoda. Presentes em todos os habitats, algumas espécies são de vida livre, enquanto outras são parasitas de plantas, do homem ou de outros animais. Entre os parasitas animais, os nematoides gastrintestinais possuem importância econômica por causarem grandes prejuízos em sistemas de produção animal (URQUHART et al., 1998).

Os principais nematoides que acometem os pequenos ruminantes são: Trichostrongylus axei e Haemonchus contortus no abomaso; 
Strongyloides papillosus, Trichostrongylus colubriformis, Cooperia pectinata, Cooperia punctata e Bunostomum trigonocephalum no intestino delgado; Trichuris ovis, Trichuris globulosa, Oesophagostomum colubianum e Skrjabinema sp. no intestino grosso. Entre esses parasitas, H. contortus, T. colubriformis, S. papillosus e O. colubianum representam maior predominância e intensidade de infecção e são considerados de maior importância econômica (COSTA et al., 2009), causadores de gastroenterite verminótica.

Entre todos os nematoides gastrintestinais de pequenos ruminantes destaca-se H. contortus que, devido ao seu hematofagismo pode levar rapidamente os animais a óbito. Esse parasita ocorre em períodos de chuvas de verão, particularmente em regiões subtropicais e tropicais (VIEIRA, 2008). É um nematoide de expressiva importância para os caprinos e ovinos, por ser o mais predominante, apresentar grande potencial biótico (capacidade de reprodução e aumento de indivíduos), grande variabilidade genética e elevada intensidade de infecção (MELO, 2005).

\subsection{Biologia parasitária dos nematoides}

\section{1. 1 Superfamília Trichostrongyloidea}

Formada por nematódeos delgados e pequenos, frequentemente capiliformes, que são classificados como bursados por possuírem bolsa copulatória. Estruturalmente, seus representantes possuem cápsula bucal pequena ou ausente, o macho com bolsa copuladora bem desenvolvida, apresentando espículos curtos e grossos (MONTEIRO, 2007). Caracterizam-se por ter um ciclo de vida direto e não migratório, são parasitas monoxenos e suas larvas no estágio infectante (larva de terceiro estagio - L3) são encapsuladas (URQUHART et al., 1998). Responsáveis por uma razoável taxa de mortalidade, acometendo prin- 
cipalmente ruminantes, localizam-se sobretudo no aparelho digestivo e respiratório. Os gêneros mais importantes são Ostertagia, Haemonchus, Trichostrongylus, Nematodirus e Dictyocaulus (SOUZA, 2013).

O gênero Ostertagia tem distribuição mundial, concentrando-se nas regiões temperadas e regiões subtropicais acometidas por chuvas no inverno. Localizando-se no abomaso, nematoides desse gênero acometem bovinos, caprinos e ovinos; são pequenos e avermelhados, quando hematófagos. Possuem ciclo biológico direto. As formas adultas põem seus ovos que são liberados nas fezes dos animais; em condições ideais, esses ovos desenvolvem-se até o estágio infectante, L3; mantendo-se em condições ideais, estes passam para a pastagem, onde serão ingeridos pelos animais, reinfectando-os (URQUHART et al., 1998). Ao serem ingeridas, as larvas continuam seu desenvolvimento, promovendo os sinais clínicos da ostertagiose de inverno. Os nematódeos da ostertagiose caracterizam-se pela penetração e desenvolvimento em glândulas gástricas, causando lesão no epitélio do estômago; os principais sinais clínicos são a diarreia, anorexia, perda de peso, edema submandibular, perda de proteínas através das lesões e anemia (SOUZA, 2013).

O gênero Haemonchus é o maior entre os gêneros da família, sendo seus representantes facilmente identificados. São nematódeos hematófagos, localizados no abomaso, causadores das maiores perdas de rebanhos de ovinos, caprinos e bovinos nas regiões subtropicais e tropicais (URQUHART et al., 1998). Seu ciclo evolutivo é direto, com fase pré-parasitária e fêmeas ovíparas. A eclosão dos ovos acontece na pastagem, onde o desenvolvimento da fase larval 1 (L1) para L3 ocorre em cinco dias; mas em condições não favoráveis esse desenvolvimento pode ser retardado (LAGARES, 2008). A haemoncose tem como aspecto principal a aguda anemia hemorrágica, levando o animal a uma perda excessiva de ferro e a uma hipoproteinemia, acarretando a perda de peso, provocada pelos hábitos hematófagos do parasita. A lesão da 
mucosa do abomaso causa uma inflamação e uma morte súbita por gastrite hemorrágica em infecções agudas (SOUZA, 2013).

O gênero Trichostrongylus é constituído por pequenos e delgados nematódeos, desprovidos de cápsula bucal, seu poro excretor situado em uma fenda visível na região anterior, sem papilas cervicais (MONTEIRO, 2007). Tem como principais espécies e hospedeiros Trichostrongylus axei, atinge equinos e suínos, $T$. columbriformis, atingindo bovinos, $T$. vitrinus e T. capricola, ovinos e caprinos, T. retortaeformis, coelhos e T. tenuis, aves de caça. Alguns representantes desse gênero parasitam o abomaso de ruminantes e provocam a tricostrongilose; outros são espécies parasitas do intestino delgado e possuem especificidade elevada ao hospedeiro (LAGARES, 2008). O desenvolvimento larval dos nematódeos desse gênero até o estágio L3 leva cerca de 7 a 15 dias. Em outras espécies de hospedeiros, esse tempo de desenvolvimento pode variar; em equinos, parasitados por T. axei, pode durar 25 dias, e em aves de caça, parasitadas por T. tenuis, somente 10 dias (SOUZA, 2013). A tricostrongilose é assintomática. As larvas penetram entre as glândulas gástricas formando túneis e causando hemorragia ao rompê-los, além de diarreia, rápida perda de peso e baixos índices de crescimento, podendo a patologia ser confundida com subnutrição (URQUHART et al., 1998).

O gênero Nematodirus tem distribuição mundial, concentrando-se em regiões temperadas (LAGARES, 2008; SOUZA, 2013). É constituído por parasitas que infectam o intestino delgado, responsáveis pela parasitose nematodirose que acomete os ruminantes. Em seu ciclo de vida, a larva desenvolve-se até L3 infectante dentro do ovo e depende de estímulos externos para eclodir. Um exemplo é a espécie Nematodirus battus, cujos ovos precisam passar por temperaturas baixas e depois amenas para que as larvas possam emergir (LAGARES, 2008). Os sinais clínicos da infecção estão relacionados às graves lesões das vilosidades intestinais e erosão da mucosa; em infecções mais graves, 
os animais apresentam diarreia, seguida por desidratação, perda de peso, baixa produção de lã em ovelhas, depressão e perda de apetite (SOUZA, 2013).

O gênero Dictyocaulus tem distribuição mundial, com maior concentração em lugares de clima temperado com verões pouco quentes e pluviosidade elevada (LAGARES, 2008). É formado por nematódeos que se encontram na traqueia, brônquios e, principalmente, nos lobos diafragmáticos dos animais parasitados. São nematódeos responsáveis pela parasitose dictiocaulose que acomete principalmente os ruminantes (bovinos e ovinos), equinos e asininos. As fêmeas desse gênero são ovovivíparas e desenvolvem ovos larvados. O desenvolvimento até a forma infectante L3 dura cerca de cinco dias; ao ser ingerida pelo animal, a larva L3 migra por meio dos linfonodos mesentéricos e ducto torácico até os pulmões (URQUHART et al., 1998). Os principais sinais clínicos da dictiocaulose são a bronquite parasitária, pneumonia, enfisema e edema pulmonar, ocorrendo exsudado mucoso, tosse e dispneia (LAGARES, 2008).

\section{1. 2 Superfamília Rhabditoidea}

Formada por espécies predominantemente de vida livre ou parasitárias, essa superfamília é considerada um grupo primitivo de nematoides. Seus representantes possuem ciclo evolutivo direto, podendo ser intercalado com ciclo de vida livre (SILVA, 2010). São nematoides pequenos, com o gênero Strongyloides apresentando importância veterinária (URQUHART et al., 1998). A forma contaminante é nomeada filarioide, enquanto a não infectante é denominada rabditoide. De acordo com as circunstâncias ambientais, as larvas infectantes L3 podem se tornar parasitas, penetrando no hospedeiro por via cutânea ou pela ingestão, instalando-se nos pulmões. Os principais sinais clínicos da parasitose 
são taxa de crescimento reduzida, anorexia, diarreia, perda de peso e/ ou apatia (URQUHART et al., 1998).

\section{1. 3 Superfamília Trichuroidea}

Nematoides dessa superfamília são encontrados em diversos animais domésticos, como mamíferos e aves. Seus representantes possuem uma característica morfológica em comum: apresentam o esôfago retilíneo, capiliforme, rodeado por uma única camada de células (URQUHART et al., 1998).

Trichuris é caracterizado como o principal gênero de helmintos dentro da superfamília Trichuroidea, devido ao fato de apresentarem distribuição mundial e alta resistência dos ovos, sobrevivendo, após três ou quatro anos, como reservatório de infecção. Comumente, são encontrados no intestino grosso de mamíferos (particularmente no ceco e cólon) em sua forma larval adulta. Apresenta formas bem peculiares, diferenciando macho de fêmea. $\mathrm{O}$ macho possui a cauda enrolada $\mathrm{e}$ uma espícula na bainha, enquanto a fêmea possui cauda curva. Ambos possuem a extremidade posterior espessa afilando-se em uma anterior filamentosa, a qual fica encravada na mucosa. Os adultos variam de $4 \mathrm{~cm}$ a $6 \mathrm{~cm}$ de comprimento. Os ovos são bem característicos, com um opérculo conspícuo, visível em ambas as extremidades, e uma coloração amarela ou castanha (MONTEIRO, 2007).

As L1 nos ovos são liberadas no ambiente e ingeridas pelo animal, tendo um período de desenvolvimento de até dois meses. Após a ingestão, o opérculo é digerido e as larvas penetram nas glândulas da mucosa do ceco com a finalidade de realizar a muda e emergir das glândulas na forma adulta (URQUHART et al., 1998).

O gênero possui diversas espécies, como T. ovis, T. globulosa, T. suis, T. vulpis e T. trichuria, tendo como hospedeiros definitivos os ovinos, 
caprinos, bovinos, suínos, cães e o homem (MONTEIRO, 2007). As infecções geralmente são leves e assintomáticas; porém, quando intensas, podem ocasionar lesão na mucosa cecal (URQUHART et al., 1998).

\section{2 Diagnóstico}

As técnicas helmintológicas em fezes são práticas de grande interesse comercial, pois avaliam a presença de ovos e larvas, podendo distingui-los uns dos outros, caracterizando-se, assim, como técnicas rotineiras, fáceis, rápidas e de baixo custo. Existem diversos métodos para se realizar o exame da presença de ovos e larvas nas fezes dos animais, destacando-se (URQUHART et al., 1998):

a) Método do esfregaço direto - sobre uma lâmina microscópica adiciona-se uma pequena quantidade de material biológico e algumas gotas de água; em seguida agita-se a lâmina para que os ovos (mais leves) flutuem, separando-se dos resíduos (mais pesados). O material é coberto por uma lamínula e analisado ao microscópio. O exame é rápido e de fácil preparação; porém, pode demandar muito tempo para a análise de todo o material e a presença de poucos parasitas torna difícil a visualização.

b) Método de flutuação - adiciona-se ao material biológico um líquido de densidade maior do que a densidade dos ovos de helmintos (o líquido utilizado precisa possuir densidade entre 1,10 ou $1,20 \mathrm{~g} / \mathrm{cm}^{3}$, sendo comumente aplicadas soluções saturadas e hipersaturadas de cloreto de sódio ou até de sulfato de magnésio) para que os mesmos fiquem na superfície do frasco; o material é homogeneizado (por agitação constante) com a solução saturada e após alguns minutos analisa-se o material em microscópio. O exame caracteriza-se como um teste qualitativo, pois indica se há presença de ovos. É um método rápido e de baixo custo; porém, é inadequado para material biológico gorduroso. 
c) Método de sedimentação simples, também chamado de técnica de Hoffmann - é uma análise qualitativa direta, baseada na sedimentação dos ovos via diluição e decantação do sobrenadante, na qual se recolhem algumas gotas do sedimento e analisa-se em microscópio eletrônico. d) Técnica de Baermann - utilizada para se extrair fases larvais vivas de nematoides em fezes; coloca-se um grama de material biológico sobre uma peneira e adiciona-se água morna dentro de um Becker (MONTEIRO, 2007).

e) Técnica de Gordon e Whitlock (1939), também chamada de técnica de McMaster ou Ovos por Grama de Fezes (OPG) - é um método que determina o número de ovos de nematoides por grama de fezes para calcular a carga parasitária de helmintos em um animal.

f) Coprocultura - realiza-se a identificação de larvas de nematoides gastrintestinais de ruminantes em seu estágio infectante (L3) após o cultivo de fezes para desenvolvimento de larvas presentes.

Outro método diagnóstico utilizado é a recuperação de parasitos adultos através da necropsia, prática de análise de parasitos retirados do intestino do animal post-mortem que revela dados precisos acerca da causa e efeito da enfermidade (PEIXOTO \& BARROS, 1998). A recuperação dos nematoides adultos do trato digestivo de ruminantes envolve colheita, contagem e identificação dos mesmos. Após a morte do animal, o trato digestivo é removido da cavidade corpórea e é dividido em três partes: o abomaso, o intestino delgado e intestino grosso. Cada órgão é avaliado e seus materiais biológicos são removidos e processados para posterior análise microscópica. $\mathrm{O}$ método de recuperação de parasitos adultos por necropsia detecta e diferencia os parasitas presentes, permitindo elucidar a causa do problema e propor métodos efetivos de combate à verminose, levando em conta que há dados concisos acerca da problemática. 


\section{3 Controle}

A verminose, doença causada por várias espécies de helmintos que parasitam o trato intestinal de caprinos e ovinos, é responsável pelos maiores problemas sanitários em criações e por prejuízos econômicos aos criadores (MOLENTO, 2013). Atualmente, o método mais utilizado pelos pecuaristas para o controle das parasitoses baseia-se na utilização de anti-helmínticos químicos associada à práticas de manejo sanitário (COSTA et al., 2009).

Os vermífugos mais utilizados podem ser classificados como de amplo espectro ou de ação específica (curto espectro). Existem quatro grandes grupos químicos de anti-helmínticos, que são: os benzimidazóis (albendazol, fenbendazol, oxfendazol), imidazotiazóis (tetramisol e levamisol), lactonas macrocíclicas (ivermectina, abamectin, doramectin, moxidectin) e salicilanilidas (closantel, disofenol, nitroxinil) (SOTOMAIOR et al., 2009). Entre eles, os benzimidazóis apresentam-se como os mais utilizados (NICIURA et al., 2010).

Aliado ao uso de vermífugos, para se obter sucesso no controle parasitário, também devem ser adotadas práticas de manejo sanitário, visando a diminuir, principalmente, a contaminação dos animais e da pastagem, bem como manter a eficiência funcional das drogas antiparasitárias (LIMA, 2011). De acordo com Molento (2004), seguem abaixo algumas estratégias a serem seguidas individualmente ou em conjunto:

- Pesar corretamente os animais: a pesagem visual, muito comum no Brasil, pode acarretar em subdoses ou desperdícios;

- É recomendado prescrever o menor número de tratamentos por ano, tanto para retardar o aparecimento de resistência parasitaria como também por motivos econômicos; 
- Fazer uso do planejamento para o tratamento tático, o qual se baseia na obtenção dos resultados da contagem de ovos por grama de fezes, para assim poder determinar a época adequada de administração do medicamento, evitando surtos parasitários;

- Alternar pastoreio entre diferentes espécies, levando em consideração que não haverá risco de infecção cruzada. Essa prática alterna, principalmente, animais ruminantes e não ruminantes mostrando-se útil para a chamada "diluição de larvas infectantes" na pastagem;

- Alternar atividades pecuárias e agrícolas com o objetivo de diminuir o número de larvas contaminantes na pastagem, criando um ambiente pouco propício a sua sobrevivência.

- Aplicar outros tipos de controle, como controle biológico, utilizando agentes como bactérias, fungos e insetos, visando a combater os mais variados tipos de pragas. A respeito desse aspecto, visar também ao uso da fitoterapia ou da homeopatia, ramos que estão atraindo pesquisadores e que têm um futuro bastante promissor.

\section{CESTODEOS}

Participantes do Filo Platyhelminthes, comumente chamados de vermes achatados, a classe dos vermes segmentados (Cestoda) é a maior existente dentro do Filo. Os cestódeos possuem corpo segmentado sem canal digestivo (alimentam-se por perfusão), com formato de fita, cada segmento contendo até dois conjuntos de órgãos reprodutores masculinos e femininos, ou seja, são hermafroditas. O corpo segmentado é dividido em escólex (para fixação), colo e estróbilo (corpo que é dividido em proglotes) e o tamanho do corpo varia de acordo com o gênero de cestódeo (de mm a metros). São parasitas obrigatórios (de 
animais), e suas formas de vida adultas localizam-se no trato digestivo do animal hospedeiro; necessitam, no mínimo, de um hospedeiro intermediário, ou seja, de um hospedeiro mediador, para completar o ciclo biológico (MONTEIRO, 2007).

O gênero Moniezia é dotado de escólex com ventosas visíveis para fixação, pescoço fino e longo, aparelho reprodutivo duplo e pode atingir de 4,5 a 6 metros de comprimento. A espécie Moniezia expansa possui importância para os sistemas de criação animal, pois tem como hospedeiros definitivos os ruminantes, e como hospedeiros intermediários, os ácaros da subordem Oribatida. Sua forma larvar é chamada de cisticercoide, e a forma adulta, cestoide, tem a capacidade de parasitar o intestino delgado, devido às glândulas interproglotidianas espalhadas nas extremidades das proglotes. Já a espécie Moniezia benedine é conhecida também por parasitar os ruminantes e ter características similares a Moniezia expansa, só que as larvas adultas possuem glândulas interproglotidianas comprimidas ao terço mediano das extremidades das proglotes (MONTEIRO, 2007).

\subsection{Biologia parasitária dos Cestodeos}

No ciclo de vida das espécies Moniezia expansa e Moniezia benedine, as proglotes grávidas ou ovos são eliminados dos hospedeiros definitivos através das fezes no pasto, são ingeridos por ácaros e nesses se desenvolvem as formas larvares. O hospedeiro definitivo se contamina, ingerindo acidentalmente os ácaros nas pastagens. As formas adultas se fixam no intestino delgado, onde ocorre a maturação e fecundação das proglotes (MONTEIRO, 2007). 


\subsection{Diagnóstico}

A infecção por espécies do gênero Moniezia é comum em cordeiros, caprinos e bezerros nos primeiros anos de vida e menos comum em animais mais velhos. Sinais evidentes da infecção são o definhamento, diarreias, sintomatologia respiratória e até mesmo convulsões. No entanto, o principal diagnóstico se baseia na presença de proglotes maduras nas fezes dos animais. Em última instância, é necessária a realização da necropsia do intestino delgado, que é aberto e imerso em água para visualização de pequenas papilas finas (URQUHART et al., 1998).

\subsection{Controle}

Prática usualmente aplicada a fim de se combater as parasitoses em pequenos ruminantes, pois embora seja pouco patogênico, o gênero Moniezia, em grandes infecções de cordeiros jovens pode levar a redução do peso corporal reduzindo assim a produtividade (MONTEIRO, 2007).

\subsubsection{Químicos antiparasitários}

Em muitos países, há uma série de drogas disponíveis para o tratamento de infecções causadas pelo gênero Moniezia, incluindo os chamados anti-helmínticos sintéticos, como niclosamida, praziquantel, e vários outros compostos benzimidazólicos de amplo espectro, que apresentam a vantagem de também serem ativos contra nematoides gastrintestinais (URQUHART et al., 1998). 


\subsection{Estratégias de manejo}

Quando os métodos de aplicação das drogas sintéticas são realizados corretamente e regularmente para o controle das infecções causadas pelo gênero Moniezia em bezerros e cordeiros, no período do final da primavera nas regiões temperadas, a quantidade de ácaros recém-infectados no pasto é reduzida. Também podem ser consideradas medidas benéficas a aração, novas semeaduras e o não uso dos mesmos pastos por animais jovens em anos consecutivos (URQUHART et al., 1998).

\section{ESTRATÉGIAS GERAIS DE MANEJO DE ANIMAIS DE PRODUÇÃO}

Para um determinado rebanho, a forma apropriada de se realizar um manejo sanitário está diretamente relacionada com a obtenção de sucesso na sua exploração. Dessa forma, é importante instituir medidas para que os animais permaneçam em equilíbrio com o parasitismo, a fim de evitar grandes prejuízos quanto à saúde animal e à produção. Nesse contexto, a limpeza dos apriscos deve consistir em práticas rotineiras na propriedade por serem imprescindíveis para evitar, controlar, diminuir e eliminar o aparecimento de doenças no rebanho, visando a reduzir o prejuízo causado por elas. A limpeza da instalação consiste na retirada de toda a sujeira (teias de aranha, restos de alimentos, fezes e insetos) existente nas paredes (divisórias), teto, piso, bebedouros, cochos e saleiros (OLIVEIRA \& ALBUQUERQUE, 2008).

A frequência com que a higienização deve ser feita depende da quantidade de animais, do tipo de piso (ripado elevado, chão batido, cimento), das circunstâncias ambientais (períodos secos ou chuvosos), da maneira como as instalações são utilizadas na propriedade e do sistema de exploração (FERNANDES, 2012). Para os apriscos, baias maternidades (onde os partos acontecem), baias enfermarias (onde os 
animais doentes são mantidos) e locais onde os cabritos e cordeiros são acomodados, é indicado que a limpeza seja feita diariamente, ou pelo menos a cada dois dias, por meio de varredura (OLIVEIRA \& ALBUQUERQUE, 2008).

A desinfecção das instalações também é imprescindível e consiste na aplicação de produtos químicos para que as chances de ocorrência de doenças diminuam. Devem ser utilizados produtos à base de amônia quaternária, hipoclorito de sódio (água sanitária), iodo ou cresol. A cal é um produto também bastante utilizado para o saneamento em instalações, devido ao seu poder germicida, além de ter baixo custo, ser de fácil acesso e aplicação (FERNANDES, 2012).

A frequência da desinfecção também está associada ao número de animais, às condições ambientais, ao tipo de piso, ao sistema de exploração e aos tipos de instalações que na propriedade são utilizadas (SOTOMAIOR et al., 2009).

Além do cuidado com a limpeza e desinfecção da propriedade, é necessária a presença de esterqueiras, construções destinadas para depósito de esterco, permitindo melhor utilização do esterco, produção de adubo orgânico, bem como contribuindo para melhorar as condições sanitárias da criação (ALVES et al., 2005). As esterqueiras não devem ficar próximas das instalações de manutenção dos animais (distância de no mínimo 150 metros), evitando a atração de insetos, a proliferação de helmintos como fonte de doenças, além do odor e da liberação de gases e amônia (FERNANDES, 2012).

Outra problemática envolvida com as estratégias de manejo é a superpopulação animal. O sistema de criação intensiva utilizado pelos pecuaristas se caracteriza como uma das principais causas responsáveis pela superpopulação nos rebanhos. Os criadores veem na superlotação de animais uma forma de obter resultados rápidos quanto ao retorno econômico, sendo este um dos erros cometidos, especialmente por pequenos criadores. Nesse sistema, uma grande quantidade de animais 
pasteja diariamente no mesmo local, defecando e depositando os ovos dos parasitos numa pequena área que é repastejada praticamente todos os dias ou com intervalos pequenos. Assim, é de se esperar que a reinfecção do rebanho aumente consideravelmente (SOTOMAIOR et al., 2009). A superpopulação de estábulos e pastagens favorece proporcionalmente a proliferação de parasitos no rebanho, causando sérios prejuízos aos animais e aos criadores e requerendo, consequentemente, mais cuidados (ALVES et al., 2013).

Além do manejo adequado dos animais da propriedade, há ainda a necessidade de cuidados diferenciados para animais recém-adquiridos. Esses animais devem passar pelo período de quarentena, em que são mantidos em uma instalação isolados dos demais animais, antes de serem inseridos ao rebanho. Essa medida é preventiva e consiste em uma série de avaliações para conhecer o estado sanitário do animal, servindo também como uma forma de adaptação gradual do animal ao ambiente, alimentação e manejo da propriedade (ALVES et al., 2013).

A ovinocaprinocultura desenvolve um papel importante na economia do país e também na subsistência de pequenos criadores. Entretanto, esses enfrentam um grande problema sanitário, a verminose, causada por helmintos gastrintestinais, responsáveis pelas maiores perdas econômicas em rebanhos (MOLENTO, 2004). Para combatê-la, alia-se um correto controle químico, utilizando vermífugos, a um manejo sanitário efetivo. Contudo, nem sempre este é realizado da maneira correta, sendo comum o uso indiscriminado de anti-helmínticos. O uso indiscriminado, aliado a um controle sanitário não eficaz, é responsável pela resistência contra antiparasitários, agente de um dos mais sérios problemas da cadeia produtiva animal (ALVES et al., 2013). 


\section{REFERÊNCIA}

ALVES, D.P. et al. Levantamento dos principais parasitos de ocorrência em caprinos no Estado do Espírito Santo. PUBVET Publicações em Medicina Veterinária e Zootecnia, Londrina, v. 7, n. 6, Ed. 229, Art. 1518, 2013.

ALVES, J. U.; CAVALCANTE, A. C. R.; SOUSA, F. B. Sistema de Produção de Caprinos e Ovinos de Corte para o Nordeste Brasileiro: Infraestrutura. Embrapa - Caprinos - Versão Eletrônica, 2005. Disponível em: <https://sistemasdeproducao.cnptia.embrapa. br> Acesso em: 13 jun. 2016.

AZEVEDO, C. F. Criação de caprinos e ovinos no Nordeste. Natal, EMPARN (EMPARN. Boletim Técnico, n.12), 1982.

CALDAS, E.M.; SANTANA, A.F.; CAETANO, A.L.S. Estudo da ovinocaprinocultura na região Nordeste do Estado da Bahia. Arquivo Brasileiro de Medicina Veterinária e Zootecnia. v. 12, p. 1-96, 1989.

CAVAlCANTE, A. C. R.; BARROS, N. N. Sistema de Produção de Caprinos e Ovinos de Corte para o Nordeste Brasileiro: Apresentação. Embrapa Caprinos - Versão Eletrônica, 2005. Disponível em: <https://sistemasdeproducao.cnptia.embrapa.br> Acesso em: 13 jun. 2016.

COOP, R.L.; KYRIAZAKIS, I. Influence of host nutrition on the development and consequences of nematode parasitism in ruminants. Trends in Parasitology, v.17, p.325-30, 2001.

COSTA, F. S. M. Dinâmica das infecções por helmintos gastrintestinais de bovinos na região do vale do Mucuri, MG. 2007. 128 f. Dissertação (Mestrado) - Instituto de Ciências Biológicas da UFMG, 2007.

COSTA, V. M. M.; SIMÕES, S. V. D.; RIET-CORREA, F. Doenças parasitárias em ruminantes no semiárido brasileiro. Pesquisa Veterinária Brasileira, v. 29, n. 7. p. 563-568, 2009. 
COSTA, V. M. M.; SIMÕES, S. V. D.; CORREA, F. R. Controle das parasitoses gastrintestinais em ovinos e caprinos na região semiárida do Nordeste do Brasil. Pesquisa Veterinária Brasileira, v.31, ed.1, p.65-71, 2011.

CUNHA, E. A. et al. Produção de ovinos para corte. Ed. 2, Nova Odessa: Instituto de Zootecnia, 2007. 141p.

FERNANDES, M. A. M.; BARROS, C. S.; VILLALBA, V. Limpeza e desinfecção de instalações - Parte I e II. Disponível em: <http:// www.farmpoint.com.br/>. Acesso em: 13 jul. 2016.

GUIMARÃES FILHO, C.; ATAIDE JÚNIOR, J. R. Manejo Básico de Caprinos e Ovinos. Serviço Brasileiro de Apoio às Micro e Pequenas Empresas - SEBRAE, p. 146, 2009.

LAGARES, A. F. B. F. Parasitoses de Pequenos Ruminantes na Região da Cova da Beira. 2008. 125 f. Dissertação (Mestrado), Universidade Técnica de Lisboa - Faculdade de Medicina Veterinária, 2008.

LIMA, A. C. Helmintoses gastrintestinais em pequenos ruminantes. 2011. 35 p. Monografia (Graduação em Medicina Veterinária) - Centro de Saúde e Tecnologia Rural, Universidade Federal de Campina Grande, 2011.

MELO, A. C. F. L. Caracterização do nematoide de ovinos, Haemonchus contortus, resistente e sensível a anti-helmínticos benzimidazóis, no estado do Ceará, Brasil. 2005. 109f. Tese (Doutorado em Medicina Veterinária- Reprodução e Sanidade Animal) - Universidade Estadual do Ceará, Fortaleza, 2005.

MOLENTO, M. B. Resistência de helmintos em ovinos e caprinos. Revista Brasileira de Parasitologia Veterinária, v. 13, suplemento 1, n. 0, p. 82-86, 2004.

MOLENTO, M. B. et al. Alternativas para o controle de nematoides gastrintestinais de pequenos ruminantes. Arquivos do Instituto Biológico, v. 80, n. 2, p. 253-263, 2013. 
MONTEIRO, S. G. Parasitologia Veterinária. Livro didático - Rio Grande do Sul: Universidade Federal de Santa Maria, ed. 2, p. 274, 2007.

MORAES NETO, O. T. et al. Manual de capacitação de agentes de desenvolvimento rural (ADRs) para a Caprinovinocultura. João Pessoa: SEBRAE/PB, 2003. p. 114

NEVES, H. H.et al. Controle de verminoses gastrintestinais em caprinos utilizando preparados homeopáticos. Revista Brasileira de Agroecologia, v. 7, ed. 1, p. 145-151, 2012.

NICIURA, S. C. M. et al. Investigação do manejo e do controle de verminose em criações de ovinos no Estado de São Paulo. Embrapa - Comunicado Técnico 95, São Paulo, 2010.

OLIVEIRA, E. L.; ALBUQUERQUE, F. H. M. A. R. Manejo Sanitário de Pequenos Ruminantes. Sobral: Embrapa Caprinos e Ovinos - Documentos Online 77, p. 27, 2008.

PEIXOTO, P. V.; BARROS, C. S. L. A importância da necropsia em medicina veterinária. Pesquisa Veterinária Brasileira, v. 52, n. 5, p. 132-134, 1998.

PINHEIRO, R. R. et al. Aspectos epidemiológicos da caprinocultura cearense. Arquivo Brasileiro de Medicina Veterinária e Zootecnia. V. 52, n. 5, p. 534-543, 2000.

POULIN, R. Evolutionary ecology of parasites. Princeton: Princeton University Press, 332p., 2007.

SAGRILO, E. et al. Agricultura Familiar: Manejo Sanitário. Embrapa - Sistemas de Produção - Versão Eletrônica, 2003. Disponível em: <http://sistemasdeproducao.cnptia.embrapa.br/>. Acesso em: 13 maio 2016.

SILVA, J. C. S. Estudos Biotecnológicos De Leite De Cabras e ambientes de produção. 2010. 129 f. Tese (Doutorado) Universidade Federal de Alagoas, 2010. 
SOTOMAIOR, C. S. et al. Parasitoses gastrintestinais dos ovinos e caprinos - Alternativas de controle. Instituto Paranaense de Assistência Técnica e Extensão Rural - EMATER, p. 27-34, f. 36, 2009.

SOUZA, F. M. Recuperação de larvas infectantes, carga parasitária e desempenho de cordeiros terminados em pastagens com distintos hábitos de crescimento. 2013. 105 f. Dissertação (Mestrado), Universidade do Rio Grande do Sul, 2013. TAYLOR, M. A.; COOP, R. L.; WALL, R. L. Veterinary Parasitology. Philadelphia: Willey-Blackwell, ed. 3, p. 600, 2007.

URQUHART, G. M. et al. Parasitologia Veterinária. Rio de Janeiro: Guanabara Koogan S. A., ed. 2, p. 262, 1998.

VIEIRA, L. S. Métodos alternativos de controle de nematoides gastrintestinais em caprinos e ovinos. Tecnologia \& Ciência Agropecuária. João Pessoa, v. 2, n. 2, p. 49-56, jun., 2008. 